\title{
Climate-Smart Chicken
}

\begin{abstract}
In the 1960s average yearly consumption of poultry meat stood at just over 3 kilograms per person on the planet. By the 1990s this had more than tripled, and by 2030 we are each predicted to be eating the equivalent of 17 kilograms of poultry meat a year (over 120 million tonnes worldwide). For every kilogram of chicken produced, up to 5 kilograms of greenhouse gas is emitted. Within this, producing the chicken feed is the main culprit at about three-quarters of the total. Each year in UK households, we waste 110,000 tonnes of chicken meat. In the developed world most chicken is produced under controlled conditions, so heat stress risks under a changing climate should be minimal. However, cooling capacities, transport systems and housing densities all need to be adapted as the risk of more extreme heat events increases. In the developing world chickens may be more exposed to severe weather impacts, but they also represent a useful way to enhance incomes and food security where resilient and higher-yielding varieties are made available.
\end{abstract}

Keywords Heat stress $\bullet$ Salmonella $\bullet$ Ventilation $\bullet$ Air-conditioning • Broilers $\bullet$ Shade $\bullet$ Transport $\bullet$ Free-range

Lunch is last night's chicken curry, scooped into a Tupperware container and re-heated in the office microwave. The bulk of the chicken we consume is produced in the same nation it is raised in-the availability of

(C) The Author(s) 2019

D. Reay, Climate-Smart Food, https://doi.org/10.1007/978-3-030-18206-9_9 
climate-controlled indoor housing methods meaning chicken can be produced on an industrial scale from the Arctic Circle to the equator.

Today's 50 billion-strong global chicken population is descended from just four species of jungle fowl domesticated in Southeast Asia over 4,000 years ago [1]. Most share a common ancestor in the so-called red junglefowl, but millennia of selective breeding have given rise to myriad varieties, from super egg layers like the Rhode Island Red, through sturdy meat chickens like the Cornish-Rock, to the poultry punk rockers that are Silkiesfluffy bundles that look like a cross between a chicken and a bag of pom-poms.

Chickens destined for the table are called 'broilers', and our appetite for their meat seems insatiable. In the 1960s average yearly consumption of poultry meat stood at just over 3 kilograms per person on the planet. By the 1990s this had more than tripled, and by 2030 , we are each predicted to be eating the equivalent of 17 kilograms of poultry meat a year (over 120 million tonnes worldwide). The biggest producers of chicken-the US, Brazil and China—are also its most avid consumers (Fig. 9.1). Average

\section{Chicken meat production, 2013}

Annual production of chicken meat, measured in tonnes per year.

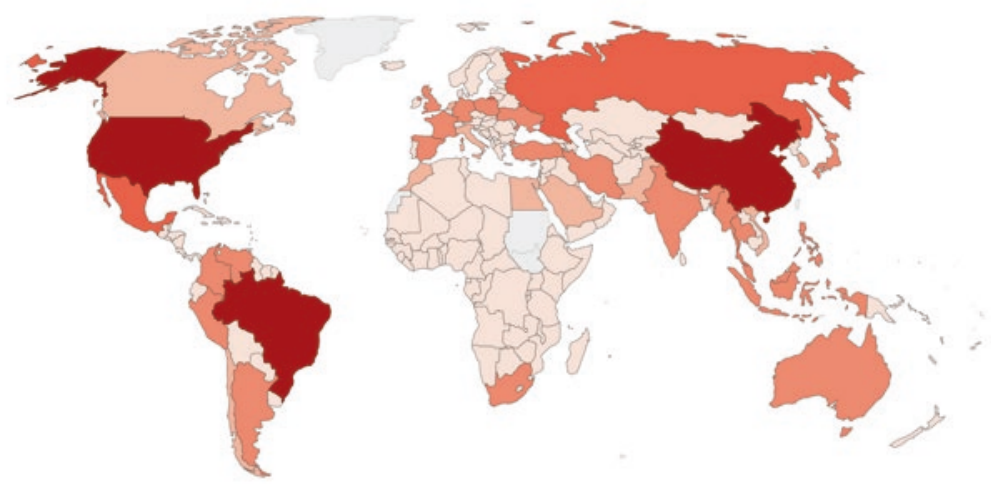

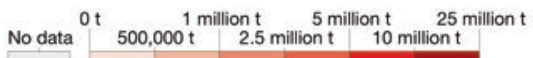

Fig. 9.1 Global chicken meat production in 2013 by country of origin (Source: Hannah Ritchie, Our World in Data) [3]. Available at: https://ourworldindata. org/grapher/chicken-meat-production 
poultry meat consumption in the US is already a bucket-busting 40 kilograms per person a year [2].

The chicken meat in our own re-heated curry started life as a free-range bird raised in large flocks in England. Although free-range eggs have become popular over the last few decades (they now make up over half of those in UK stores), free-range chicken meat is still a niche commodity at under 5 per cent of UK production [4]. The bulk of chicken meat is instead produced in 'barn-raised' systems. These have a higher densityaround 17 birds per square metre of sawdust-covered floor space-and, unlike free-range chickens, have no access to the outdoors. In both cases, commercial farmers aim to rush their poultry through-from new-born chick to oven-ready adult-in the most efficient way possible. Through careful selection of fast-growing traits combined with precisely controlled feeding regimes, modern farms are now able to grow a chicken to slaughter-ready size in under 40 days.

The chicks are hatched in incubators and for the first few weeks of life need warm and humid conditions, with the required temperature of around 32 degrees Celsius being achieved in controlled-atmosphere sheds. At one day of age, they are moved to the growing sheds and each is passed through a vaccination spray. The standard diet for barn-raised chickens consists of copious supplies of high-protein mash, crumbs or pellets. These are derived from a mix of cereal grains, like maize and wheat, along with vegetable and animal proteins like soy and fishmeal [5]. Various fats, minerals and vitamins are incorporated to boost energy contents and ensure good bone and muscle development. For free-range birds, a more varied diet including weeds and insects is possible. Controversially, many commercial chicken farmers also add antibiotics to feeds, along with $\mathrm{pH}$ control agents and enzymes to aid feed digestion [6].

Air-conditioned housing means temperature and humidity can be controlled to maximise growth and, for most commercial farms, this means keeping the chickens in windowless fan-ventilated barns. Good ventilation and thorough cleaning between batches are vital to avoid a dangerous build-up of ammonia from the poultry faeces - too much ammonia can lead to respiratory and eye damage [7]. Even under the controlled conditions of the broiler houses, an average of 3 in every 100 birds die during the rearing phase.

With a relatively short distance between the barn and our supermarkets, it is the on-farm production of broiler chickens that dominates their overall carbon footprint $[8,9]$. For every kilogram of chicken produced, up to 5 
kilograms of greenhouse gas is emitted. Within this, producing the chicken feed is the main culprit at about three-quarters of the total. During its short life, the average barn-raised table bird will consume more than double its own slaughter weight in feed. Free-range and organic birds consume closer to five times their final weight (as they have longer lives) and so, per drumstick, thigh and wing have a higher carbon footprint than their barn-raised cousins [10]. Soy meal from Brazil and Argentina is the main component of this feed and makes up almost half of its emissions, the rest coming from wheat, vegetable oils and fishmeal.

Given the heavy use of heating, ventilation and air conditioning by commercial producers, the use of electricity and gas are the next biggest source of emissions on the chicken farm. Housing, land use and manure complete the carbon footprint. It is, however, chicken manure's pungent plumes of ammonia that spread downwind of the farms that may pose the greatest environmental risk. Carried on the wind, the ammonia is deposited to fields, woodlands and lakes where it can damage sensitive species like lichens and mosses, and push up overall ecosystem nutrient levels (eutrophication). As an added bonus, it may boost nitrous oxide emissions too [11].

Once the chickens have reached market weight, they are transported to slaughterhouses, then to meat-processing plants, and on to retailers. Each of these phases adds a further 500 grams or so of emissions per kilogram of chicken produced, mainly through the fuel and energy used [8]. The final destination of the chickens, our households, appears as a relatively minor part of the total chicken meat climate impact. Refrigeration and cooking on average add just 350 grams of emissions per kilogram to the overall footprint. But, as with almost every type of food we consume, wastage then rears its ugly head.

For my siblings and me in 1970s' Britain, roast chicken was a special Sunday dinner treat. Ever hungry, our eyes grew wide as we watched our dad carefully carve the bird and lay slices of meat on our plates. The top privilege was to be given the Parson's nose-the fatty arrow-shaped base of the chicken's tail. Next most joyous (and often a recipe for stomach ache) was to clear your plate first and have prime picking of the carcass. Our small fingers became expert at peeling any remaining slivers of meat from the bones and nibbling the skin from wingtips.

Several decades of improved feeds, faster growth rates and industrial production methods have made chicken more of a staple than a Sunday treat. At the time of writing, a whole chicken can be bought in the UK for 
just $£ 3$. This incredibly low price has helped drive the huge increase in our consumption and along with it a lot more wastage.

Each year in UK households, we waste 110,000 tonnes of chicken meat. This is all avoidable. It is edible meat that doesn't get eaten because it has either gone past its use-by date (32,000 tonnes), because too much was cooked and served (46,000 tonnes), or simply because we didn't fancy chicken after all (13,000 tonnes) [12]. Some also ends up in the garbage because it is burned or spoiled. At 5 kilograms of greenhouse gas per kilogram of chicken, this Great British poultry wastage has a staggering carbon cost: half a million tonnes of emissions a year. It also means the equivalent of 85 million chickens are hatched, intensively reared, slaughtered, processed and sent to the shops, all to then end up in the bin [10].

A focus for cutting this poultry waste mountain down to size has been the huge amount that goes out of date before it can be eaten. Packaging can really help-separate compartments for chicken pieces, for instance, could slice 10,000 tonnes off British chicken waste simply by allowing us to use one side and freeze the other [13]. For whole birds, many chefs and recipe books have also been trying to help households make use of every last bit [14].

As chickens are produced all over the world, they face a wide array of climate risks. Heat is the big one for most, and the threats posed by higher temperatures can go far beyond the farm gate. From accelerated growth of dangerous spoilage bacteria like Campylobacter and Salmonella, to more barbecues and the inherent risks of an undercooked drumstick, hotter summers could ramp up the risks to our own health [15]. Climate-smart solutions must therefore make farms more resilient to severe weather impacts, lower carbon footprints, and better protect the health of birds and humans alike [16].

Food poisoning is unpleasant at the best of times. Poisoning from chicken meat can be deadly. The US Centers for Disease Control and Prevention estimate that around 1 million people become ill each year due to the eating of contaminated chicken [17]. With the surge in consumption, chicken has consequently become the meal most commonly involved in outbreaks of food poisoning. Poultry were associated with one quarter of the more than 1,000 outbreaks recorded in the US between 1998 and 2012. The bacteria Salmonella accounted for the most illnesses and 
hospitalisations, and the second highest number of deaths (Listeria being the number one food poisoning killer) [18]. Some of the more recent US outbreaks that involved high rates of hospitalisation have resulted from antibiotic-resistant strains of Salmonella.

Although contamination can occur during production and processing, many of the cases of food poisoning due to eating chicken are a result of poor storage, handling and undercooking [18]. Climate change, and especially higher temperatures, may accelerate the growth of spoilage organisms like Salmonella. Infections are already more common in summer and appear to peak during periods of warm weather. Where refrigeration is inadequate or the time between preparation and cooking is too long, the bacteria can multiply to dangerous levels. Salmonella poisoning commonly results in fever, diarrhoea and abdominal cramps [16]. In the UK there are an estimated 39,000 cases each year, but this represents a big decrease compared to the early 1990s. Right across Europe Salmonella poisoning appears to be on the decline thanks to improved food hygiene, better biosecurity, and the widespread vaccination of animals. Climate change is not expected to reverse this downward trend, though a 10 to 15 per cent increase in cases across Europe is possible by the 2080s under a very high warming scenario. In Australia, spiritual home of the barbecue, a more serious climate impact is likely. Here, an extra 4,000-7,000 cases of food poisoning per year by the middle of the century are predicted, and in South Australia, incidences of Salmonella may rise by more than 50 per cent [16].

With air-conditioned barns and carefully controlled atmospheres, most commercial chicken farms in the developed world might be expected to be at low risk from high temperatures and other direct climate change impacts [19]. Certainly, these systems are designed to protect the birds from weather extremes, giving as close to optimal conditions as possible to ensure maximum growth. Heat waves in the summer mean a rise in energy costs for cooling and ventilation, but warmer winters may cut winter heating bills. As climate change intensifies, it is the severity of the heat waves, and the risks of heat stress both in the barns and during transport, that represent one of the biggest threats-the 2003 European heat wave killed an estimated four million broiler chickens in France alone [20].

Today's commercial meat chicken is genetically distinct from those bred in the 1990s and before. It consumes a lot of feed, grows much faster and has a smaller heart relative to its body weight. It is therefore more sensitive to high temperatures and more susceptible to heart failure [21]. 
At the high stocking densities of commercial barns, the birds produce a lot of heat, and this needs to be actively managed. If the excess warmth is not efficiently removed, then the first signs of heat stress will quickly appear.

Initially a heat-stressed chicken will increase its water consumption, direct more blood supply to its comb, and try to move away from other birds. It may seek out cooler surfaces and areas where there is greater airflow. Given room it will open its wings and try to expose more of its feather-free skin to the air. If it is still too hot the chicken will begin to pant and so shed more heat via evaporation. As the temperature rises still higher, so the rate of panting quickens and the bird becomes lethargic. With no respite it will die. Chickens like it warm-they have an internal temperature of 41 degrees Celsius-but an increase of 4 degrees Celsius or more above this is fatal [22].

As well as temperature, the humidity of the atmosphere in the broiler houses is a big risk factor. As humidity rises, the ability of the birds to cool themselves through evaporation falls. Damp and soiled bedding can exacerbate this humidity problem and lead to dangerous increases in ammonia in the barn air [23]. Even mild heat stress over an extended period is a serious economic issue for the farmer, as well as being a major animal welfare one. Heat-stressed chickens will eat less, have lower feed conversion efficiency, and so grow more slowly [24]. Their immune systems will also be suppressed, making them more susceptible to infection and disease.

The perfect storm of broiler heat stress impacts comes when high stocking densities combine with very hot weather and inadequate airconditioning. Closely confined chickens are up to 40 per cent less efficient at shedding heat, and if the capacity of the barn's cooling and ventilation systems is exceeded, dangerous heating will occur. Farmers tend to plan their stocking densities months in advance, and so an unexpectedly intense summer heat wave may overwhelm the standard cooling systems they have in place [22].

The last leg of a meat chicken's life-that from barn to slaughterhouse-adds further heat exposure risks. An estimated 1.8 million (2 in every 1,000 ) birds die in transit in the UK each year, with occasionally very high losses of more than 15 per cent reported. Heat stress plays a major role, with a pronounced peak in mortality during the summer months. Most birds are transported to slaughter in closely packed containers consisting either of loose crates or of modular stacks of metal drawers. Limited ventilation and space to move means the birds have less ability to keep 
themselves cool. As daily maximum outside temperatures rise above 17 degrees Celsius, so mortality rates tend to rise. Even in the low 20s Celsius, the mortality rate may double and above that it can increase more than sixfold [25].

Thankfully, large-scale chicken death incidents due to heat waves have tended to become less frequent in the developed world, with the use of improved barn designs, modern ventilation systems and improved transport practices. Tragedies still occur though, such as the loss of 50,000 chickens in North Carolina when power was lost for just one hour during the heat wave of 2011 [26] and the more than 6,000 birds that perished on a single farm in southern England in 2012 due to overstocking and inadequate ventilation during hot weather [27].

Often less apparent than these direct effects of extreme heat have been the effects of severe weather events on poultry feed. With feed being so reliant on staple crop ingredients like soy and wheat, severe weather events like droughts and heat waves can lead to shortages in supply and so sharp spikes in prices [28]. For chicken farmers in the developed world then, future climate change, and especially higher temperatures, poses risks to the welfare of their flocks and to productivity, as well as to feed and energy costs.

In the developing world the risks may be much greater. Here, access to modern housing and air-conditioning systems is often more limited. In some rural areas power supplies may be unreliable or non-existent. For commercial poultry farmers in already-hot regions of Africa and Asia, concern is growing that climate change and more intense heat waves will increasingly threaten livelihoods and the welfare of birds and humans alike [29].

Many smallholders in rural areas use chickens as an extra source of protein and income to supplement their normal farming. Their birds are more likely to be free ranging and the housing to have no active cooling and ventilation. Most chickens will scavenge for food rather than being given feed, and in general, their growth rates are low compared to birds on commercial farms. They are also more prone to disease, parasites, and to being attacked by predators [19]. During periods of intense heat, free-range chickens will usually respond by seeking shade. However, if this shaderetreat is for prolonged periods and no additional feed is supplied, then their nutrition may suffer. In some areas changing precipitation and higher temperatures may also combine to reduce the availability of food that can be scavenged by the chickens as they roam. With food and income 
from chickens often providing the final safety net from poverty for rural smallholders, avoiding reduced productivity and increased mortality due to the impacts of climate change can yield big social benefits.

Achieving climate-smart chicken production inevitably requires contextspecific approaches. For large commercial units in the UK and other developed nations, planning ahead for extremes of heat and ensuring that housing, transport and management practices are fit for purpose are at the core. While close attention to forecasts and severe weather warnings can help give a few days to check cooling and ventilation before a heat wave hits, longer term planning for lower stocking densities in the summer months may be much more effective. Output from the farms may be lower, but they can better avoid the heat stress risks caused by too many chickens and very high temperatures coinciding. Some farmers already thin out their numbers in expectation of hot weather to allow the remaining birds to keep cool. Many have improved the insulation and thermal performance of their barns, taking account of its positioning in the landscape and how reflective the roof materials are [30]. Good insulation has the multiple benefits of lowering heating costs in winter, buffering extreme outside heat in summer, and reducing condensation and damp-related issues inside the barns.

Making use of natural shade from trees may also be beneficial during the hottest days - this is especially true for free-range systems where the birds need areas of shade they can retreat to in the heat of the day. So too can using narrow barns (to aid ventilation air flow) and ensuring that air intakes for ventilation and cooling are located in the best locations (such as shaded walls) to draw in cool air.

The features of the landscape surrounding the chicken farm can play a much wider role in just how climate-smart it is. Poorly maintained access roads, inadequate manure storage and leaky grain silos all make the farm more vulnerable to storms and intense rainfall events-flooding having the potential to block roads, spoil feed, and cause pollution of streams and rivers through surface runoff. To limit the plumes of ammonia gas emitted from commercial broiler farms, good manure management is key. This involves regular cleaning of the sheds and treatment of soiled bedding to make it more acidic (so reducing how much ammonia is lost to the air). Strategic planting of tree 'capture belts' downwind of the broiler sheds can 
also be an effective way to intercept the ammonia carried on the wind. In some cases this type of 'poultry agroforestry' has the potential to boost tree growth, and so carbon uptake, of the farm too [31].

Building design and location features can therefore help reduce the overall amount of mechanical cooling and ventilation required, but in commercial systems some kind of air-conditioning system will still be needed. During hot weather an effective ventilation system keeps the air over the chickens moving, taking with it heat and moisture that could otherwise build up and cause heat stress problems. It means that, when the birds pant, their evaporative cooling is much more effective with the feeling of wind chill from the air movement also serving to make the birds more comfortable.

Many older barns do not have such active cooling systems and rely more on natural ventilation via openings along the length of the barn. In very hot weather internal fans that circulate the air more can help make the birds feel more comfortable, though these fans do not provide new air from outside and so risk a dangerous build-up of moisture, carbon dioxide and ammonia in the barn's atmosphere [22].

To make the most of the benefits of evaporative cooling, misting sprays are sometimes used. These can be a very effective way of avoiding the panting response of the birds to high temperatures, and so keeping feeding and growth rates going strong. The downside of these water spray systems is that, at very high temperatures, they can actually make things worse-raising the humidity to a level where the birds cannot cool themselves at all. Most commercial farms now use alarm systems that warn when cooling and ventilation equipment fail, or when temperature and humidity are approaching dangerous levels. The alarms either trigger automatic back-up cooling or warn the farmer to start up failsafe plans (like the use of generators during a power cut) [22].

Day to day, good practice during hot weather periods depends very much on the expertise of the commercial chicken farmer. For instance, leaving the ventilation system running all night may seem a waste of money and energy, but then these costs may pay big dividends in terms of greater comfort and survival rates of the birds during the heat of the following day. Likewise, reducing or completely removing feed during the hottest hours of the day could reduce growth rates, but may also limit overheating in the birds and the numbers which then succumb to heat stress [22].

The capture and onward transport of broiler chickens to the slaughterhouse can be a very stressful experience and, as we've seen, there remains 
a real danger of heat stress during this final stage of the chicken's life. Rapid capture and transport coinciding with the coolest part of the day helps reduce heat stress risks, and postponing things until the weather cools and the birds are in a less stressed state can also pay big dividends. During transport, ensuring proper ventilation, drinking water and adequate space are a must, as is avoiding the travel modules and their vehicle being left standing in direct sunlight.

All of these responses have the potential to yield greater resilience to extreme weather, can reduce heat stress risks and mortality rates, and so boost productivity. Through better hen welfare, the energy and feed inputs-representing the largest part of a broiler chicken's carbon footprint-will also be more efficient. Implementing some of the technical solutions, like mechanical ventilation and super-insulated housing, requires significant upfront costs, and so, the availability of finance is important. More crucially, informed planning and practices to deal with increasing heat stress risks require good training and ready access to advice on weather forecasts and best practice.

For millions of rural smallholders around the world, chickens represent an opportunity to boost incomes and the overall resilience of households. In Nyando-a largely rural district of Kenya-keeping chickens has actually become a cornerstone of climate-smart activities for many families [32]. The average household keeps 30 birds that largely scavenge for their food and are indigenous to the area (and so can thrive even with minimal feed and healthcare). An increasing number of women in these households are now farming a crossbred type of chicken that matures faster than the indigenous ones (they reach market weight in one-third of the time). Combined with training on the construction and maintenance of better housing, provision of feed, and more disease control and treatment, the scheme is already proving a success. This innovative 'climate-smart chicken' initiative is enabling the women of Nyando to build more resilience into their livelihoods even as the threats to their other crops from climate change increase-the chickens represent a feathered form of household savings and insurance against times of heavy crop losses, with the manure they produce being a valuable fertiliser to boot.

So, the climate future of the world's chicken dinners appears safe, albeit one where the welfare of the birds and safety of their meat requires renewed attention. A bigger question is to what extent the staggering growth in chicken meat consumption in the twentieth century will continue through the twenty-first. The push for more sustainable diets is 
certainly gaining momentum, with very high-carbon meats like beef and lamb sitting right in the emissions reduction bullseye. Vegetarianism and veganism may be gaining ground, but there's little sign that we'll be turning our backs on the finger-licking delights of chicken any time soon.

\section{REFERENCES}

1. PennState. History of the Chicken. Pennsylvania State University Extension. https://extension.psu.edu/history-of-the-chicken (2011).

2. thepoultrysite.com. Global Poultry Trends 2014: Growth in Chicken Consumption in Americas Slows. http://www.thepoultrysite.com/articles/ 3324/global-poultry-trends-2014-growth-in-chicken-consumption-in-americas-slows/ (2015).

3. Ritchie, H. Global chicken meat production, 2013. Ourworldindata.org. https://ourworldindata.org/grapher/chicken-meat-production (2018).

4. Castella, T. Do people know where their chicken comes from? BBC Online. https://www.bbc.co.uk/news/magazine-29219843 (2014).

5. poultryhub.com. Feed Ingredients. http://www.poultryhub.org/nutrition/ feed-ingredients/ (2019).

6. poultryhub.com. Feed Additives. http://www.poultryhub.org/nutrition/ feed-ingredients/feed-additives/ (2019).

7. Aziz, T. \& Barnes, H. J. Harmful effects of ammonia on birds. Poultry World. https://www.poultryworld.net/Breeders/Health/2010/10/Harmfuleffects-of-ammonia-on-birds-WP008071W/ (2010).

8. Skunca, D., Tomasevic, I., Nastasijevic, I., Tomovic, V. \& Djekic, I. Life cycle assessment of the chicken meat chain. J. Clean. Prod. 184, 440-450 (2018).

9. MacLeod, M. et al. Greenhouse Gas Emissions from Pig and Chicken Supply Chains-A Global Life Cycle Assessment, 171 (Food and Agriculture Organization of the United Nations (FAO), Rome, 2013).

10. Leinonen, I., Williams, A., Wiseman, J., Guy, J. \& Kyriazakis, I. Predicting the environmental impacts of chicken systems in the United Kingdom through a life cycle assessment: Broiler production systems. Poult. Sci. 91, 8-25 (2012).

11. Reay, D. Nitrogen and Climate Change: An Explosive Story (Springer, 2015).

12. WRAP. Household food and drink waste in the United Kingdom 2012. Waste and Resource Action Programme. http://www.wrap.org.uk/sites/files/wrap/ hhfdw-2012-main.pdf.pdf (2013).

13. WRAP. Packaging design to reduce household meat waste. Waste \& Resources Action Programme. http://www.wrap.org.uk/sites/files/wrap/packaging design_to_reduce.pdf (2012).

14. Seal, R. How to make a chicken last a week. The Observer. https://www.theguardian.com/lifeandstyle/2017/apr/09/how-to-make-a-chicken-last-aweek-angela-hartnett (2017). 
15. Lake, I. et al. Food and Climate Change: A Review of the Effects of Climate Change on Food Within the Remit of the Food Standards Agency (Food Standards Agency, 2010).

16. Lake, I. R. Food-borne disease and climate change in the United Kingdom. Environ. Health 16, 117 (2017).

17. CDC. Chicken and Food Poisoning. https://www.cdc.gov/features/salmonellachicken/index.html (2018).

18. Chai, S., Cole, D., Nisler, A. \& Mahon, B. E. Poultry: The most common food in outbreaks with known pathogens, United States, 1998-2012. Epidemiol. Infect. 145, 316-325 (2017).

19. Nyoni, N., Grab, S. \& Archer, E. R. Heat stress and chickens: Climate risk effects on rural poultry farming in low-income countries. Clim. Dev., 1-8 (2018).

20. García-Herrera, R., Díaz, J., Trigo, R. M., Luterbacher, J. \& Fischer, E. M. A review of the European summer heat wave of 2003. Crit. Rev. Environ. Sci. Technol. 40, 267-306 (2010).

21. Zhang, J., Schmidt, C. J. \& Lamont, S. J. Gene expression response to heat stress in two broiler lines. Anim. Ind. Rep. 662, 61 (2016).

22. DEFRA. Heat Stress in Poultry: Solving the Problem. Department for Environment, Food \& Rural Affairs, UK. https://assets.publishing.service. gov.uk/government/uploads/system/uploads/attachment_data/ file /69373/pb10543-heat-stress-050330.pdf (2005).

23. PoultryWorld. Harmful Effects of Ammonia on Birds. https://www.poultryworld.net/Breeders/Health/2010/10/Harmful-effects-of-ammonia-onbirds-WP008071W/ (2010).

24. Lara, L. \& Rostagno, M. Impact of heat stress on poultry production. Animals 3, 356-369 (2013).

25. Warriss, P., Pagazaurtundua, A. \& Brown, S. Relationship between maximum daily temperature and mortality of broiler chickens during transport and lairage. Br. Poult. Sci. 46, 647-651 (2005).

26. Hegeman, R. Heat wave kills thousands of poultry. Huffington Post. https:// www.huffingtonpost.com/2011/07/13/heat-wave-poultry_n_896812.html (2017).

27. BBC. Paul Flatman Banned after Chelmsford Chicken Heat Deaths. https:// www.bbc.co.uk/news/uk-england-essex-32847446 (2015).

28. Hill, C. Free range egg farmers battle rising feed costs after hot, dry summer. Eastern Daily Press. http://www.edp24.co.uk/business/farming/free-rangepoultry-rising-feed-costs-bfrepa-1-5655114 (2018).

29. Bhadauria, P. et al. Impact of hot climate on poultry production system-a review. J. Poult. Sci. Tech. 2, 56-63 (2014).

30. Fairchild, B., Vest, L. \& Tyson, B. L. Key factors for poultry house ventilation. thepoultrysite.com. http://www.thepoultrysite.com/articles/2321/key-factors-for-poultry-house-ventilation/ (2012). 
31. Bealey, W. et al. The potential for tree planting strategies to reduce local and regional ecosystem impacts of agricultural ammonia emissions. J. Environ. Manag. 165, 106-116 (2016).

32. Recha, J. \& Kimeli, P. Chicken to the Rescue: How Farmers in Nyando are Managing Climate Risks. CGIAR Climate Change, Agriculture \& Food Security. https://ccafs.cgiar.org/blog/chicken-rescue-how-farmers-nyandoare-managing-climate-risks\#.XOxQjS2ZPUo (2017).

Open Access This chapter is licensed under the terms of the Creative Commons Attribution 4.0 International License (http://creativecommons.org/licenses/ by $/ 4.0 /$ ), which permits use, sharing, adaptation, distribution and reproduction in any medium or format, as long as you give appropriate credit to the original author(s) and the source, provide a link to the Creative Commons licence and indicate if changes were made.

The images or other third party material in this chapter are included in the chapter's Creative Commons licence, unless indicated otherwise in a credit line to the material. If material is not included in the chapter's Creative Commons licence and your intended use is not permitted by statutory regulation or exceeds the permitted use, you will need to obtain permission directly from the copyright holder.

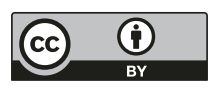

